\title{
FÅNGTAL OCH KRIMINALPOLITIK I HOLLAND
}

\author{
Av PROFESSOR, JUR.DR. HANNS VON HOFER
}

The Dutch prison population has increased by a factor of five during the last 25 years. Since there are no accepted general theories to explain this development, the paper starts from the assumption that the increase in the Dutch prison population has served an explicit political objective. A scenario is then presented in the hope of making it easier to understand why the change in Dutch prison politics - from decarceration to incarceration - became politically acceptable. *

I mitten av 1970-talet lät Nordiska Samarbetsrådet för Kriminologi undersöka frågan varför Holland hade så få människor i fängelse. Den holländska statistiken visade då mycket låga siffror i jämförelse med andra länder. År 1975 uppgick exempelvis antalet fångar i Finland till 111 per 100.000 invånare, i Danmark till 67, i Sverige till 61, i Norge till 48, men i Holland bara till 19. Samtidigt hade fångpopulationen i Sverige under perioden 1955-1975 ökat från 45 till 51 fångar per 100.000 invånare, medan den i Holland hade i det närmaste halverats från 35 till 19.

Vilka var då förklaringarna till de stora skillnaderna (se von Hofer, 1975)? De låga holländska siffrorna kunde inte förklaras med att fångar "doldes" i mentalsjukhus, alkoholistanstalter eller andra liknande institutioner. Däremot förklarade olika långa vistelsetider cirka 80 procent av skillnaden mellan fångtalen. I Holland var de ådömda och faktiskt avtjänade strafftiderna kortare än i Sverige. I genomsnitt löd en fängelsedom i Holland på tre månader och i Sverige på fem. Den faktiska tiden en intagen verkligen stannade i fängelse uppgick i Holland till 1 1 $1 / 2$ månader och i Sverige till fyra. Resten av skillnaden (ca 20 procent) fick inte någon helt entydig förklaring. Möjligen spelade den eventuellt lägre holländska brottsnivån någon roll. Även åklagarnas större möjligheter att avskriva fall och underlåta åtal kan ha varit av betydelse. Ett annat viktigt resultat av jämförelsen var att själva brottsutvecklingen inte kunde förklara skillnaden mellan länderna. Både i Holland och Sverige hade den registrerade brottsligheten (brottsbalksbrotten) ökat mellan 1955 och 1975 - i Holland med en faktor 3,5 och i Sverige med en faktor 2,5.

Undersökningen stannade vid en beskrivande analys och sökte inte efter några djupare förklaringar utanför kriminalstatistiken. Vid ungefär samma tidpunkt förklarade dock den holländska fångvårdsmyndigheten nedgången bl.a. med att åklagarna, som intar en central roll i det holländska rättssystemet, följde en uttalad policy att hålla allt fler lagöverträdare utanför rättsmaskineriet.

\footnotetext{
* Title in English: Prison Population and Prison Politics in The Netherlands. Original in Swedish.
} 
Detta på grund av övertygelsen om fängelsestraffets stigmatiserande och allmänt skadliga effekter. Synsättet var också accepterat i pressen, den allmänna opinionen och i domarkåren. Underströmmarna till dessa attityder ansåg den holländska fångvårdsmyndigheten ligga i en generell trend mot större tolerans $\mathrm{i}$ det holländska samhället (Netherlands Prison Administration, 1973).

Denna typ av förklaring har senare många utländska observatörer tagit fasta på. Baring (1976) skrev exempelvis, att det holländska straffsystemet jämfört med det engelska helt enkelt var mildare. Han ansåg att skälen till den större toleransen var historiska och geografiska. Sedan 1500-talet hade Holland varit en tillflyktsort för religiösa och politiska flyktingar av alla schatteringar. Universiteten har alltid förkunnat toleransens dygd. Holland utmärks av en lång tradition av socialvård och kriminalvårdsreformer. Dessutom satt under andra världskriget många medborgare i fängelse och i åtanke av denna erfarenhet skulle det ha funnits en övertygelse om fängelsernas meningslöshet och förnedring. Speciellt många holländska domare hade spärrats in av den tyska ockupationsmakten. Denna unika historiska erfarenhet hjälpte - enligt Smith (1977) - möjligen till att överbrygga avståndet mellan domarna och de åklagade och skulle kunna förklara varför domarkåren fortsatte att begränsa fängelsestraffets användning.

Typiskt är också följande citat från ett forskningsseminarium om amerikanska och holländska fängelser (Netherlands Criminal Justice Investigate Seminar, 1978):

Nationalkaraktären betonar personlig frihet, tolerans och socialt ansvar. Landets socioekonomiska system minimerar inkomstskillnader och otrygghet. Arvet efter de holländska kyrkorna gynnar en känsla av ömsesidig respekt och omtanke, och kyrkorna förser dess medlemmar med förebyggande och stödjande hjälp och ställer upp med försvar i rättssaker. [...]

I Holland anses fängelser vara skadliga institutioner som man inte skall förlita sig på alltför mycket. Fängelsestraffet är den sista utvägen. Domare har som rättesnöre att minsta skada skall göras; socialarbetare anser att 'fängelser är inte bra' och till och med åklagare hyser uppfattningen att fängelsernas effekter är huvudsakligen eller enbart negativa. Holländsk press och programansvariga på TV undviker överdrivna skildringar av brott och brottslingar.

Korta straff är nyckeln till Hollands låga fångpopulation. [...] På varje nivå i det holländska straffrättssystemet uppmuntras beslutsfattarna att använda urskillning för att undvika att individer dras in i straffsystemet. (Min översättning)

År 1982 publicerade sedan David Downes (1982) en systematisk analys av holländsk fångvårdspolitik efter andra världskriget. ${ }^{1}$ Han urskilde sju olika förklaringsmodeller i diskussionen om de holländska fängelserna: (1) Decarceration avinstitutionalisering som en möjlig generell trend i västliga samhällen; (2) The limits of penal capacity - tesen om att den faktiska tillgången på fängelseplatser styr fångpopulationen och inte tvärtom; (3) The culture of "tolerance" - beskrivningen av det holländska samhället som - exceptionellt - tolerant; (4) The politics of accomodation - påståendet att ständiga koalitionsregeringar skulle ha lett 
till en effektiv neutralisering av "lag \& ordning"-frågan; (5) Confluence uppfattningen att holländsk påföljdspolitik inte är resultat av en systematisk politisk planering utan konsekvens av ett myller av olika omständigheter; (6) The culture of the judiciary och (7) The rise and fall of rehabilitation - den holländska domarkårens stora betydelse med dess utpräglat negativa inställning till fängelsestraffets användning. Downes (1982:355) avslutade sin analys med att konstatera:

\footnotetext{
Sammanfattningsvis kan urskiljas tre faser i fångvårdspolitiken i efterkrigstidens Holland. Den första fasen, som sträckte sig från tidigt 1950-tal till mitten av 1960-talet, präglades av en behandlings- och anti-straffilosofi som förklarar trenden mot kortare straff. Under den andra fasen, från ungefär mitten av 1960-talet till mitten av 1970-talet, föranledde bl.a. platsbristen domarkåren att fortsätta med förkortningen av strafftiderna. Under den tredje perioden, från och med det sena 1970-talet, har förkortandet av strafftiderna upphört och trycket växer att utöka fängelsesystemets kapacitet. (Min översättning)
}

Vid ungefär samma tidpunkt noterade Johnson \& Heijder (1983) att brottsligheten i Holland ökade brant och att det fanns en utbredd fruktan att utländska kriminella skulle kunna invadera holländsk mark för att dra fördel av de låga straffen där. Fängelsepopulationen började öka, fast inte i samma utsträckning som brottskurvan. "Framtiden får utvisa om ökningen är tillfällig eller inte" (Johnson \& Heijder, 1983:18).

Med facit i handen kan vi konstatera att slutet av 1970-talet varit brytningsperioden för holländsk fängelsepolitik (jfr Fiselier, 1992; Baerveldt \& Bunkers, 1996; Junger-Tas, 2001). Mellan 1975 och 2001 ökade medelbeläggningen i de holländska fängelserna i princip utan avbrott från 19 till 95 fångar per 100.000 invånare. Fångantalet har femfaldigats och Holland ligger numera i paritet med Tyskland och tydligt över de nordiska länderna. Bara Spanien, England och Portugal uppger ännu högre fångtal bland de 15 EU-länderna (SPACE, 2002). Därmed finns det anledning att på nytt ta upp "fallet Holland"; speciellt toleranshypotesen har visat sig oförmögen att förutse den kraftiga ökningen av fångantalet. Först dock en kort kriminalstatistisk beskrivning av uppgången.

\section{Uppgången}

Att beskriva utvecklingens kriminalstatistiska aspekter är inte helt enkelt eftersom holländsk kriminalstatistik delvis är svårgenomtränglig och statistikomläggningar och redovisningsförändringar komplicerar jämförelser över tid. Ändå skall ett försök göras. 
Tabell 1. Holland: Utdömda fängelsestraff och fångvårdsstatistik, 1975-1999. $\begin{array}{llllll}1975 & 1980 & 1985 & 1990 & 1995 & 1999\end{array}$

Domstolsstatistik

Ovillkorligt fängelse

\& delvis villkorligt fängelse $14797 \quad 15369 \quad 16351 \quad 19147 \quad 25281 \quad 27343$

Fångvårdsstatistik

\begin{tabular}{|c|c|c|c|c|c|c|}
\hline Intagningar & 17283 & 22874 & 23087 & 31219 & 32523 & 42251 \\
\hline Medelbeläggning & 2526 & 3234 & 4599 & 6616 & 9646 & 11673 \\
\hline Vistelsetid (dagar) & 53 & 52 & 73 & 77 & 108 & 102 \\
\hline
\end{tabular}

I Tabell 1 ligger fångvårdsstatistikens uppgifter om intagningar delvis betydligt högre än domstolsstatistikens uppgifter avseende personer som dömts till fängelse. Bortsett från att det kan finnas antalsräknings- och kvalitetsproblem är skillnaden åtminstone delvis reell, eftersom holländska intagningsdata - till skillnad från domstolsstatistiken - också omfattar bl.a. häktade, personer som skall avtjäna ett kort bötesförvandlingsstraff, civilrättsliga/konkursrättsliga frihetsberövanden samt utländska medborgare som tas i förvar. Värt att notera är också att ökningen av fängelsedomarna år 1995 inte framgår i motsvarande grad av intagningsstatistiken. Medelbeläggningen har stigit kraftigare än intagningstalen, vilket innebär att den genomsnittliga vistelsetiden har ökat. Grovt räknat har den faktiska vistelsetiden fördubblats sedan 1980, från genomsnittligt 52 dagar till över 100 dagar i slutet av perioden.

Tabell 2. Holland: Antal fängelsedomar enligt strafftidens längd (i månader), 1975-1999.

\begin{tabular}{lrrrrrr}
\hline Strafftid & 1975 & 1980 & 1985 & 1990 & 1995 & 1999 \\
& & & & & & \\
upp till 11 månader & 14182 & 14548 & 14783 & 17028 & 21579 & 24003 \\
12 - 35 månader & 502 & 646 & 1281 & 1507 & 2732 & 2417 \\
36 månader och fler & 113 & 175 & 287 & 612 & 970 & 923 \\
& & & & & & \\
TOTALT & 14797 & 15369 & 16351 & 19147 & 25281 & 27343 \\
\hline
\end{tabular}

Källa: Huls m.fl. (utan år), Tab. 4.11 (s. 345)

De ökande vistelsetiderna hänger i sin tur ihop med att antalet korta frihetsstraff har reducerats genom alternativa sanktioner (Tak, 2001) samtidigt som domstolarna dömer ut fler längre fängelsestraff. Speciellt har de långa fängelsestraffen ökat och ökningen har inte korrigerats med exempelvis ändrade regler om 
villkorlig frigivning. ${ }^{2}$ Kvarstår frågan i vilken mån de längre strafftiderna är en följd av att brottsbilden har förändrats och/eller av att domstolarna skärpt straffen. Exakta kriminalstatistiska uppgifter finns tyvärr inte tillgängliga, varför facklitteraturen har anlitats (Haen Marshall, 1988; Kalmthout, 1992; SagelGrande, 1995; de Haan, 1997; Kruize, 1997; Junger-Tas, 2001). Sammanfattningsvis kan konstateras att båda förklaringarna är giltiga till ungefär lika delạr.

\section{Fångtal och politik}

Många empiriska studier har visat (jfr Westfelt, 2001), att det inte råder någon automatik mellan utdömandet och verkställigheten av frihetsstraff. Därför ställer en ökande användning av frihetsstraff ansvariga politiker inför problemet om och i vilken omfattning denna också skall leda till en ökad fångpopulation. Till skillnad från böter och icke-frihetsberövande sanktioner är frihetsstraffet en mycket kostsam sanktionsform. Det måste finnas nödvändigt förvaringsutrymme för att kunna verkställa frihetsstraffet. Uppgiften är således att hitta en politiskt godtagbar balans mellan "utbud" (antal fängelseplatser) och "efterfråga" (antal frihetsstraff).

Ekvationen kan lösas på flera olika sätt. Inflödet till anstalterna kan regleras genom att alternativ till frihetsstraff införs. Frihetsstraffets avtjänande kan skjutas upp för en del dömda via köbildning; blir kön för lång kan en del i kön benådas. Fler personer kan tas in på fängelserna genom att fångar hyses i tillfälliga lokaler eller genom att flera fångar måsta dela cell. Platsbeståndet kan också ökas permanent genom till- och nybyggnation. Slutligen kan själva vistelsetiden förkortas bl.a. genom utökad villkorlig frigivning eller benådning. Valmöjligheterna är alltså stora och den avgörande frågan är, vilka alternativ som anses som politiskt gångbara och därmed genomförbara. Holländska politiker har valt andra metoder när det gäller att reglera fångpopulationens utveckling jämfört med exempelvis politikerna i Norden, där fångpopulationerna hållits relativt stabila (Danmark, Norge och Sverige) eller sänkts drastiskt (Finland, se LappiSeppälä, 1998).

\section{Den holländska politiken}

År 1972 minskades fängelsekapaciteten som en del av en generell omstrukturering av systemet. Kapacitetsminskningen sammanföll dock med ett faktiskt växande behov av fler fängelseplatser. 1972 års beslut resulterade i en allvarlig brist på fängelseceller och personer dömda till korta fängelsestraff benådades kollektivt samtidigt som verkställigheten av korta fängelsestraff alltmer drog ut på tiden (Haen Marshall, 1988; Baerveldt \& Bunkers, 1996).

I februari 1981 tillsattes en arbetsgrupp (Capacity Problems in the Prison Service) vilken ett år senare föreslog permanenta kapacitetsökningar (SCP 1982). År 1983 krävde en stor majoritet i parlamentets Andra kammare av den borgerliga koalitionsregeringen - bestående av kristdemokrater och liberaler - 
en plan för att upprätthålla lag och ordning. I motionen motiverades kravet (1) med den växande oron i befolkningen för brottsökningen; (2) med risken att allmänheten förlorar förtroendet för regeringen och dess roll som garant för enskilda och allmänna intressen; samt (3) med farhågor om en pågående urholkning av medborgarnas föreställningar om normer och social kontroll (Ministerie van Justitie, 1985). Den s.k. Roethof-kommittén tillsattes (jfr. Tak, 2001), och det avgörande steget mot en höjning av fångtalet togs sedan 1985 i Justitiedepartementets programförklaring "Society and Crime. A policy plan for The Netherlands" som i sin tur byggde på preliminära förslag från Roethof-kommittén.

I policyplanen ${ }^{3}$ konstaterades att kriminaliteten i Holland hade ökat mycket starkt, i synnerhet när det gäller den organiserade kriminaliteten som ansågs ligga bakom mycket av den narkotikarelaterade brottsligheten i form av egendoms- och våldsbrott. Kriminalitetsökningen samt minskade resurser för rättsväsendet uppfattades ha lett till dramatiskt sjukande effektivitet inom rättsväsendet, vilket i sin tur urholkat straffsystemets allmänna trovärdighet och preventiva funktion. Djupgående förändringar skulle därför vara nödvändiga. En dubbelstrategi föreslogs. Kontrollen av småbrottslighet skulle föras över i lokalsamhällets regi (jfr. Sarnecki, 1990), medan allvarlig brottslighet skulle bekämpas med intensifierade straffrättsliga medel genom ökad upptäcktsrisk, fler åtal och strängare straff. I konsekvens härmed föreslogs också ett långtgående ny- och utbyggnadsprogram för fängelserna.

\footnotetext{
Justitieministern har tvingats konstatera att straffsystemet inte längre är kapabelt, med dess nuvarande resurser, att upprätthålla en miniminivå av lagtillämpning vilket är nödvändig $\mathrm{i}$ en rättsstat. Gapet mellan antalet brott och faktiskt verkställda straff har blivit oacceptabelt stort.

I nuvarande situation är det inte bara omöjligt att vidmakthålla avskräckning och normförstärkning på en adekvat nivå, det måste också befaras att den ständigt lurande möjligheten att medborgarna tar lagen $i$ egna händer inte längre kan kontrolleras. [...]

Ordningen måste återställas på straffrättens område. (Ministerie van Justitie, 1985:20; min översättning)
}

Utbyggnadsplanerna och resursökningen till fångvården genomfördes (se Tabell 3) och den inslagna vägen bekräftades i en förnyad policyplan år 1990. I planen konstaterades torrt: "Trots myndigheternas ansträngningar att angripa orsakerna till ökningen i fängelsepopulationen [...], kommer det att bli nödvändigt att företa ytterligare kapacitetsökningar [...]. - Det förväntas finnas ungefär 12.000 celler allt som allt år 1996" (Netherlands Ministry of Justice, 1990:70 f). Förväntningarna har faktiskt infriats, vilket framgår av Tabell 3. Holländska bedömare (t.ex. van Kalmthout \& Tak, 2001a) drar den rimliga slutsatsen att utbyggnaden av fängelseplatserna lett till en strukturell ökning av fångpopulationen i Holland, som med stor sannolikhet kommer att bestå en längre tid framöver. 
Tabell 3.Holland: Platstillgång i fängelser och kostnader för fängelseväsendet, 1970-2000.

$\begin{array}{lllllll}1970 & 1975 & 1980 & 1985 & 1990 & 1995 & 2000\end{array}$

Antal platser

Förändring (i procent)

Kostnader (mil. EUR)

Justitiedepartementets

budget totalt (mil. EUR)

Andel (i procent)
4037

3440

\section{3}

4997

$$
71951020812617
$$

$118 \quad 165$

$+16$

$+25$

$+43+41+24$

118

221

218

$330 \quad 520 \quad 1000$

\section{5}

1915
\# Trolig överskattning p.g.a. redovisningsförändring. Det sanna värdet torde ligga kring 20 procent.
Not. Kostnader är uttryckta i Euro i 2000 års penningvärde.

Källor: von Hofer (1998:170); DJI $(2001: 11,13)$

\section{Varför - ett förklaringsförsök}

Vilka anses då de underliggande skälen vara till strategiändringen i det till synes liberala och fängelsefientliga Holland? I avsaknad av hållbara teorier om fångpopulationers generella utveckling (jfr. Tonry, 2002) blir eventuella förklaringar ad hoc. Jag väljer som utgångspunkt tesen (jfr. Rutherford, 1996a), att ökningen av fängelsepopulationen har varit en uttalad politisk målsättning. Inom loppet av ungefär 10 år - mellan cirka 1975 och 1985 - skedde en principiell strategiändring i holländsk kriminalpolitik - från avfolkning till inspärrning. Vilka skulle rambetingelserna för en sådan ändring kunna ha varit? Ur tillgänglig holländsk litteratur kan följande möjligt scenario härledas på vilket sätt situationen uppfattades av beslutsfattarna.

Policyplanen 1985 publicerades i slutet av en period, då Holland upplevt en mycket djupgående ekonomisk kris i början av 1980-talet. Mellan 1980 och 1984 hade antalet arbetslösa ökat från ca 260.000 till över 800.000 . Efterkrigstidens exceptionellt starka ekonomiska tillväxt var slut - med omfattande ekonomiska besparingar (Haen Marshall m.fl., 1990; Kalmthout, 1992) och långtgående politiska attitydförändringar som följd. Junger-Tas (2001:188) skriver:

\footnotetext{
Samtidigt som välfärdsstaten sedan början av 1980-talet alltmer kom att ersättas av marknaden, vilket innebar att statens ansvar gentemot medborgarna minskade och framhävandet av individuellt ansvar starkt ökade, skiftade också uppfattningarna om orsakerna till brottsligt beteende - från orsaker i lagöverträdarens sociala bakgrund, livssituation och omständigheterna kring brottet till gärningsmannens moraliska skuld, fri vilja och fulla ansvar. (Min översättning)
}

Men redan under de tidigare tillväxtåren uppfattades grundvalen för det traditionella holländska samhället ha utsatts för starka påfrestningar, vilka ytterligare förstärktes i mitten av 1970-talet genom invandring (Junger-Tas, 1997; de Haan, 1997) och etablering av narkotikaproblemet (Leuw, 1991; Korf, 1995). Den 
samtidigt kraftigt stigande brottsligheten sattes i samband med en allomfattande sekulariseringsprocess och söndervittrandet av de s.k. "pelarna" samt det ökande materiella överflödet, proteströrelserna och transformationen från tolerans till permissivitet under 1960- och 1970-talen (de Haan, 1997).

Rättssystemet ansågs inte kunna möta de växande kraven på ökad kontroll då resurserna var feldimensionerade och målsättningen med straffrättsliga ingripanden diffus. Sanktionsrisken upplevdes minska kraftigt genom avtagande upptäcktsrisk, likaså sannolikheten att ett utdömt straff gick i verkställighet. Speciellt det sista förhållandet, att häktade släpptes och att utdömda fängelsestraff inte verkställdes alls eller först åratal efter domen, skapade offentlig upprördhet och "bad will" för rättsväsendet. "Det behövs knappast sägas att inte ta häktade i förvar utgör ett upprörande brott mot en grundläggande rättsstatlig princip, nämligen att beslut utfärdade av domare också måste verkställas" (Ministerie van Justitie, 1985:16). ${ }^{5}$

Till skillnad från 1960- och 1970-talen, där kriminalpolitiska frågor inte stod i förgrunden för pressens och politikernas uppmärksamhet (Johnson \& Heijder, 1983; Steenhuis m.fl., 1983) och där rättsväsendets funktionärer tämligen obehindrat kunde utöva sin "tolerans från ovan" (Christie, 1996:39), blev lag och ordning en "het" politisk fråga (Beki m.fl., 1999:403). Massmedia och politiker kom allt starkare att betona betydelsen av en effektiv kriminalitetskontroll, varvid uppfattningen att droghanteringen utgjorde en central faktor för brottsligheten spelade en nyckelroll (Haen Marshall m.fl., 1990): det överallt synliga narkotikabruket hade gett upphov till småkriminalitet och ordningsstöranden som av allmänheten upplevts som irriterande och oroande. Junger-Tas (2001:188) sammanfattar:

Andra har observerat att det holländska rättsväsendet och justitiedepartementet under lång
tid styrts av en liberal och tolerant elit av experter, lagstiftare och höga tjänstemän. [...]
Denna situation förändrades dock dramatiskt i takt med att utsattheten för vardaglig
småbrottslighet ökade. Dessutom blev brottsligheten ett centralt och användbart tema i
medierna. [...] Trycket på regeringen, parlamentet och domarkåren att stifta hårdare lagar
och att döma ut längre straff har ökat kraftigt. (Min översättning)

Anmärkningsvärt är också, att det uppenbarligen inte fanns något organiserat politiskt motstånd mot nybyggnadsplanerna, vilket påpekas av Franke (1990). En stark alliansen av fängelsepersonal, fångar, fångorganisationer och påtryckningsgrupper mot införandet av gruppceller (som ett medel att skapa plats på fängelserna) hjälpte faktiskt till att bana vägen för nybyggnadsprogrammet. Delvis på grund av detta enhälliga motstånd fick justitieministern ge upp planerna att inrätta gruppceller vilket skulle ha accepterats av en stor majoritet $\mathrm{i}$ parlamentet. "Kritiken mot nybyggnadsplanerna utdefinierades som politiskt oansvarig, och så dog den" (ibid, s. 90).

Till denna inhemska utveckling lades sedan också det tryck som utövats ifrån 
internationellt håll (framför allt från Frankrike, Sverige, USA och dåvarande Västtyskland) att överge den liberala narkotikapolitiken (Downes, 1988; Fiselier, 1992; Baerveldt \& Bunkers, 1996). "Fram till tidigt 1980-tal verkade den holländska drogpolitiken röra sig allt längre ifrån kontrollstrategierna i andra västländer. Holland bidrog till sin isolering genom att överdriva den liberala bilden på det internationella planet" (Haen Marshall m.fl., 1990:411).

\section{Analys}

Har då kursändringen i holländsk fängelsepolitik varit framgångsrik? Avsikten här är inte att åstadkomma en regelrätt utvärdering av holländsk kriminalpolitik. Snarare skall det ställas några indikatorer över brottsutvecklingen, straffanvändning, straffverkställighet och kostnader mot allmänhetens uppfattningar dokumenterade i opinionsundersökningar. Ur snäv demokratisk synvinkel bör ju en politik kunna betecknas som lyckad när politiken (till synes) uppnår resultat som står i överensstämmelse med folkliga föreställningar och krav samt om folkflertalet också uppfattar att målen har uppnåtts.

\section{Kriminalpolitiska åtgärder}

Sedan mitten av 1980-talet har offerundersökningar med avseende på våld, stöld och skadegörelse visat ett stort mått av stabilitet (SCP, 2001) - ställt mot ökningarna under perioden innan, medan framför allt våldsbrott fortsatte att öka enligt polisens brottsstatistik (van Praag \& Uitterhoeve, 1999). Under 1990-talet liknar bilden den i många andra europeiska länder (Westfelt, 2001; Barclay \& Tavares, 2002): stöldbrotten stabiliseras på hög nivå, medan våldbrotten fortsätter att öka i polisstatistiken (SCP, 2001). Nyare specialundersökningar har inte kunnat bekräfta existensen av en utbredd organiserad brottslighet (Fijnaut, 1990; SCP, 1995) eller ökande narkotikamissbruk (Leuw, 1991; Korf, 1995) två områden som spelat stor roll i den kriminalpolitiska diskussionen i Holland. I ett internationellt perspektiv framstår Holland som ett land med lågt "problem drug use" (EMCDDA, 2001).

Antalet poliser är litet i ett internationellt perspektiv och uppklaringsprocenten har varit kontinuerligt fallande (van Dijk \& de Waard, 2000; SCP, 2001). Ändå straffas numera fler personer och fler döms till fängelse med genomsnittligt längre strafftider och resurserna till rättsväsendet och fängelserna har fördubblats mellan 1995 och 2000 (se ovan Tabell 1-3).

På lagstiftningsområdet framkommer under 1990-talet en klar tendens mot högre maximistraff samt utvidgningar av det straffbara området när det gäller organiserad kriminalitet, miljö- och trafikbrottslighet, vissa typer av våld och ordningsstöranden (Albrecht, 1999; van Kalmthout \& Tak, 2001b). Sedan 1999 gäller också en ny kriminalvårdslag som tonar ned rehabilitering som ett verkställighetsmål på bekostnad av säkerhet och drogfrihet (Pakes, 2000; Tak, 2001).

Vid sidan av de repressiva åtgärderna har de holländska regeringarna sedan 
mitten av 1980-talet allt mer satsat på förebyggande åtgärder som kriminalpolitisk strategi (Willemse, 1997; van Dijk, 1999), och efter många års diskussion genomfördes år 1994 en omfattande polisreform (van Praag \& Uitterhoeve, 1999). Stödinsatser för brottsoffer koordinerades redan i mitten av 1980-talet genom inrättandet av "The National Association of Victim Support Services" och verksamheten har utvecklats mycket kraftigt under 1990-talet (SCP, 2001).

I ett teknokratiskt perspektiv framstår den holländska kriminalpolitiken således som målinriktad och kraftfull. Downes' tidigare beskrivning av att holländsk kriminalpolitik inte var resultat av systematiskt politisk planering (utan konsekvens av ett myller av olika omständigheter), bör numera bytas mot den motsatta beskrivningen (jfr van Swaaningen \& de Jonge, 1995): kriminalpolitiken kännetecknas idag i hög grad av vad i litteraturen betecknas som "managerialism", dvs. en byråkratisk filosofi driven av större kostnadsmedvetenhet och mer planering tillsammans med en allt mer uttalad inriktning på effektiva former av politisk reglering och social kontroll (jfr. Cavadino \& Dignan, 1997:222) - varvid den växande skara av planerings- och utvärderingskriminologer spelar en betydande roll. Andrew Rutherford (1996b) sammanfattar:

I Nederländerna [...] förlorade den socialliberala modellen i popularitet som ersattes av
moraliserande lag och ordnings-retorik och en politik av planerad rättvisa. [...] Etiska vär-
deringars betydelse för kriminalpolitiken under 1990 -talet har blivit mer osäker. Den popu-
listiska dagordningen i kombination med trycket från managerialismen har bidragit att för-
svaga och kanske till med avskaffa de gränser som skyddade samhället från att söka mer
förenklade och auktoritära lösningar på brottsligheten. (Cit. efter Criminal Justice Abstra-
cts; min översättning)

\section{Opinionsundersökningar}

Har då omläggningen av kriminalpolitiken sedan mitten av 1980-talet gett utdelning i den allmänna opinionen? I Holland finns en lång tradition för undersökningar av detta slag, vilket ger goda möjligheter att beskriva opinioners förändring över tid. Över lag visar undersökningarna att allmänheten oroar sig över brottsligheten: att bekämpa brottsligheten ges högsta prioritet och polisarbete rankas högt bland de politikområden som regeringen bör ansvara för. Det verkar högst osannolikt att 70-talets avkriminaliseringstendenser skulle ha vunnit fotfäste hos den holländska allmänheten (SCP, 1995) - tvärtom: ur opinionsundersökningarna framträder bilden att en överväldigande majoritet i Holland uppfattar brottsligheten som ett allvarligt och framför allt växande problem. År 1980 var 79 procent av de tillfrågade av denna uppfattning, år 1993 hade denna andel ökat till 92 procent (SCP, 1995). Det allmänna förtroendet för polisen är sett $i$ ett internationellt perspektiv - lågt (van Kesteren m.fl., 2000: Tab. 21 \& 22). Däremot tycks upplevelserna av den personliga (o)säkerheten inte förändrats mycket sedan 1970-talet (Vanderveen, 2001; se även SCP, 2001 och van Kesteren m.fl., 2000: Tab. 23 \& 24). 
Även inställningen till syftet med straffrättsliga ingripanden har ändrats påtagligt över tid. På frågan om det primära syftet skulle vara att "rehabilitera" eller "straffa" lagöverträdaren föredrog i början av 1970-talet 72 procent rehabiliteringen. I början av 1990-talet hade denna andel sjunkit till knappt hälften, 49 procent (SCP, 1995). Speciellt tydligt är attitydförändringen gentemot sexualbrottslingar. År 1970 förespråkade 68 procent av de tillfrågade "behandling", i slutet av perioden ansåg 52 procent att sexualbrottslingar i första hand bör straffas (ibid). Mellan 35 och 44 procent (ingen trend) anser att det kanske vore en bra idé att återinföra dödsstraffet för vissa brottstyper (ibid). Enligt de internationella offerundersökningarna (ICVS) finns i Holland (tillsammans med England, Skottland och Nordirland) numera också förhållandevis många som förordar ett fängelsestraff för en 21-årig som vid sitt andra inbrott stulit en färg-TV jämfört med tillfrågade i andra europeiska länder. I Holland uppgick år 1999 andelen till 37 procent jämfört med exempelvis 19 procent i Finland, 20 procent i Danmark och 31 procent i Sverige (år 1988 var för Holland motsvarande andel 26 procent; van Kesteren m.fl. 2000, Tab. 27).

Resultatet tycks vara att varken de tidigare borgerliga regeringarna (fram till 1996) eller den senaste socialdemokratiska (1996-2002) lyckats få grepp om opinionen. Visserligen är det knappast möjligt för vanliga medborgare och ickeexperter att skaffa sig realistiska uppfattningar om hur rättsväsendet är dimensionerat, hur det arbetar och hur framgångsrikt insatserna är. Ändå förefaller det anmärkningsvärt att en så "konsumenttillvänd" kriminalpolitik som den holländska misslyckats att lugna opinionen. Den "inre säkerheten", dvs. frågor om ordning och reda, brott och straff har inte kunnat avföras från den politiska dagordningen och kom inte minst att användas av Pim Fortuyn ${ }^{6}$ i parlamentsvalet våren 2002.

\section{Avslutning}

I mångt och mycket påminner utvecklingen och situationen i Holland om den uppmärksammade analysen som Kathrine Beckett (1997) gjort av kriminalpolitikens utveckling i USA: här som där stigande opinioner för straffåtgärder, kraftigt ökande utgifter för rättsväsendet och (sky)höga fångtal som i stor utsträckning drabbar minoriteter. ${ }^{7}$ För USA:s del ifrågasatte Beckett starkt den vanliga tesen ("democracy-at-work"), att kriminalpolitikens utveckling i USA huvudsakligen skulle kunna förstås som politikernas reaktiva svar på folkliga krav. En motsvarande analys kvarstår att göras för Hollands del. Möjligen kan dock preliminärt hävdas att där kom krav på ändring delvis underifrån - åtminstone när det gäller situationen i början av 1980-talet (se beskrivningen ovan). Men det var knappast något folkligt krav att mångdubbla fångpopulationen. Samtidigt tycks det holländska exemplet tyda på att "kampen mot brottsligheten" är svår att vinna opinionsmässigt - både för borgerliga och socialdemokratiska regeringar. Jag håller tesen (jfr Pantazis, 2000; Estrada \& Nilsson, 2001) 
för sannolik att "oro för brott" och krav på "lag och ordning" åtminstone delvis kan tolkas som ställföreträdande begripliga uttryck för en mer grundläggande existentiell oro, som är så mycket svårare att hantera politiskt - eller med Kathrine Becketts (1997:108) ord i fri översättning: Ekonomiskt tryck, oro inför sociala förändringar och en omfattande känsla av otrygghet skapar stor frustration. I en sådan situation har det alltid varit relativt lätt att avleda sådana känslor med att skylla på underklassen och minoriteter.

\section{LITTERATUR}

Albrecht, H.J. (1999): Penal Policies and Penal Sanctions: A Look at Developments and Trends in Europe. I: Hood, R. \& Courakis, N.E.: The Changing Face of Crime and Criminal Policy in Europe. Occasional Paper No. 19, s. 1-23. [Oxford:] University of Oxford/Centre for Criminological Research.

Baerveldt, C. \& Bunkers, H. (1996): Limits to growth: The case of Dutch prison capacity, Crime, Law \& Social Change, Årg. 25, s. 153-172.

Barclay, G. \& Tavares, C. (2002): International comparisons of criminal justice statistics 2000. Home Office Statistical Bulletin 05/02. London: Home Office.

Baring, J. (1976): The recent trends towards reducing the prison population in The Netherlands: an English viewpoint, International Journal of Offender Therapy and Comparative Criminology, Årg. 20, s. 80-96.

Beki, C., Zeelenberg, K. \& van Montfort, K. (1999): An Analysis of the Crime Rate in The Netherlands 1950-93, British Journal of Criminology, Årg. 39, s. 401-415.

Beckett, K. (1997): Making Crime Pay. Law and Order in Contemporary American Politics. New York/Oxford: Oxford University Press.

Cavadino, M. \& Dignan, J. (1997): The Penal System. 2:a uppl. London: Sage.

CBS (1996): Gevangenisstatistiek 1995. Voorburg/Heerlen: Centraal Bureau voor de Statistiek.

Christie, N. (1996): Kriminalitetskontrol som industri. På vej mod GULAG, vestlig stil. København: Hans Reitzels Forlag.

van Dijk. J.M. (1999): Trends in Crime Prevention: Some Lessons from The Netherlands. I: Hood, R. \& Courakis, N.E.: The Changing Face of Crime and Criminal Policy in Europe. Occasional Paper No. 19, s. 57-66. [Oxford:] University of Oxford/Centre for Criminological Research.

van Dijk , F. \& de Waard, J. (2000): Legal infrastructure of The Netherlands in international perspective. Crime control. [The Hague:] Directorate for Strategy Development/Ministry of Justice The Netherlands.

DJI (2001): Jaarverslag 2000. Samenverken aan en visie. Den Haag: Dienst Justitiële Inrichtingen.

Downes, D. (1982): The Origins and Consequences of Dutch Penal Policy Since 1945, British Journal of Criminology, Årg. 22, s. 325-362.

Downes, D. (1988): Contrasts in Tolerance. Post-war Penal Policy in The Netherlands and England and Wales. Oxford: Clarendon Press.

Downes, D. (1990): Response to Herman Franke, British Journal of Criminology, Årg. 30, s. 94-96.

Estrada, F. \& Nilsson, A. (2001): Brottslighet som välfärdsproblem - Utsatthet för brott och oro för brott 1988-1999. I: Ofärd i välfärden. Antologi från Kommittén Välfärdsbokslutet. SOU 2001:54, s. 223-263. Stockholm: Fritzes.

EMCDDA 2001 (2001): Annual report on the state of the drug problem in the European Union. Luxembourg: Office for the Official Publication of the European Communities.

Fijnaut, C.J.C.F. (1990): Organized Crime: the form it takes, background and methods used to control it in Western Europe and the United States. I: G. Kaiser and H.-J. Albrecht, Crime and Criminal Policy in Europe. Proceedings of the II. European Colloquium, s. 53-103. Crimino- 
logical Research Reports by the Max Planck Institute for Foreign and International Penal Law. Volume 43. Freiburg: Eigenverlag Max-Planck-Institut.

Fiselier, J.P.S. (1992): A Test of the Stability of Punishment Hypothesis: The Dutch Case, Journal of Quantitative Criminology, Årg. 8, s. 133-151.

Franke, H. (1990): Dutch Tolerance. Facts and Fables, British Journal of Criminology, Årg. 30, s. 81-93.

de Haan, W. (1986): Det nederlandske fängselssystem, Nordisk Tidsskrift for Kriminalvidenskab, Årg. 73, s. 193-206.

de Haan, W. (1997): Minorities, Crime and Criminal Justice in the Netherlands. I: I. Haen Marshall (red.), Minorities, Migrants, and Crime: Diversity and Similarity Across Europe and the United States, s. 198-223. Thousand Oaks: Sage.

Haen Marshall, I. (1988): Trends in Crime Rates, Certainty of Punishment and Severity of Punishment in the Netherlands, Criminal Justice Policy Review, Årg. 1, s. 21-52

Haen Marshall, I., Anjewierden, O. \& van Attevald, H. (1990): Toward an 'Americanization' of Dutch Drug Policy?, Justice Quarterly, Årg. 7, s. 391-420.

von Hofer, H. (1975): Dutch Prison Population. I: 17:e nordiska forskarseminariet $i$ Kriminologi 1975, s. 104-150. Stockholm: Nordiska Samarbetsrådet för Kriminologi.

von Hofer, H. (1998): Fångtal och kriminalpolitik i Holland och Sverige. I: von Hofer. H. (red.), Brottsligheten i Europa, s. 160-177. Lund: Studentlitteratur.

van der Heide, W. \& Groen, P.P.J. [utan år]: Tenuitvoerlegging van sancties. I: Huls, F.W.M., Schreuders, M.M., ter Horst-van Breukelen, M.H. \& van Tulder, F.F. (red.): Criminaliteit en rechtshandhaving 2000. Ontwikkelingen en samenhangen. Onderzoek en beleid 189, s. 109-132. [Utan ort:] CBS/WODC.

Huls, F.W.M., Schreuders, M.M., ter Horst-van Breukelen, M.H. \& van Tulder, F.F. (red.) [utan år]: Criminaliteit en rechtshandhaving 2000. Ontwikkelingen en samenhangen. Onderzoek en beleid 189. [Utan ort:] CBS/WODC.

Johansson, R. (1994): Nederländerna, Staatsskick och politik. I: Nationalencyklopedin, Band 14, s. 87. Höganäs: Bokförlaget Bra Böcker, 1994.

Johnson, E.H. \& Heijder, A. (1983): The Dutch Deemphasize Imprisonment: Sociocultural and Structural Explanantions, International Journal of Comparative and Applied Criminal Justice, Årg. 7, s. 3-19.

Junger-Tas, J. (1997): Ethnic Minorities and Criminal Justice in the Netherlands. I: Tonry, M. (red.), Ethnicity, Crime and Immigration. Comparative and Cross-National Perspectives. Crime and Justice. A Review of Research, Årg. 21, s. 257-310.

Junger-Tas, J. (2001): Dutch Penal Policies Changing Direction. I: Tonry, M. (red.), Penal Reform in Overcrowded Times, s. 179-189. Oxford/New York: Oxford University Press.

van Kalmthout, A.M. (1992): The Netherlands. I: Anton M. van Kalmthout \& Peter J.P. Tak, Sanctions-Systems in the Member-States of the Council of Europe. Part II. Deprivation of liberty, community service and other substitutes. International Penal and Penitentiary Foundation. Deventer, Boston: Kluwer Law and Taxation Publishers.

van Kalmtouth, A.M. \& Tak, P.J.P. (2001a): Prison Population Growing Faster in the Netherlands than in the United States. I: Tonry, M. (red.), Penal Reform in Overcrowded Times, s. 161168. Oxford/New York: Oxford University Press.

van Kalmtouth, A.M. \& Tak, P.J.P. (2001b): New Sanctions Proliferating in the Netherlands. I: Tonry, M. (red.), Penal Reform in Overcrowded Times, s. 175-179. Oxford/New York: Oxford University Press.

van Kesteren, J., Mayhew, P. \& Nieuwbeerta, P. (2000): Criminal Victimisation in Seventeen Industrialised Countries. Key findings from the 2000 International Crime Victims Survey. Onderzoek en beleid 187. The Hague: NSCR/WODC.

Korf, D.J. (1995): Dutch Treat. Formal control and illicit drug use in the Netherlands. Amsterdam: Thesis Publishers.

Kruize, P. (1997): Den hollandske fængselspolitik, Nordisk Tidsskrift for Kriminalvidenskab, Årg. 
84, s. 188-194.

Lappi-Seppäla, T. (1998): Regulating the Prison Population. Experiences from a Long-Term Policy in Finland. Reaerch Communications 38. Helsinki: National Research Institute of Legal Policy.

Leuw, E. (1991): Drugs and Drug Policy in the Netherlands. I: M. Tonry, Crime and Justice. A Review of Research, Årg. 14, s. 229-276. Chicago: University of Chicago Press.

Ministerie van Justitie (1985): Society and Crime. A policy plan for The Netherlands. Schiedam: van Rossum.

Netherlands Criminal Justice Investigate Seminar (1978): How Holland supports its low incarceration rate: the lessons for us. [Stencil]

Netherlands Ministry of Justice (1990): Law in Motion. A policy plan for Justice in the years ahead. Information Department. The Hague.

Netherlands Prison Administration (1973): The decrease in the population of Dutch penitentiary establishments. Gravenhage.

Pakes, F.J. (2000): League Champions in the Mid Table: On the Major Changes in Dutch Prison Policy, The Howard Journal, Årg. 39, s. 30-39.

Pantazis, C. (2000): Fear of Crime, Vulnerability and Poverty, British Journal of Criminology, Årg. 40, s. 414-436.

van Praag, C. \& Uitterhoeve, W. (1999): 25 years of social change in the Netherlands. Key data from the Social and Cultural Report. Nijmegen: SUN.

Rutherford, A. (1996a): The Problematic Relationship Between Crime and Imprisonment, Nordisk Tidsskrift for Kriminalvidenskab, Årg. 83, s. 105-109.

Rutherford, A. (1996b): Transforming Criminal Policy. Winchester: Waterside Press.

Sagel-Grande, I. (1995): Das niederländische Strafensystem. Gesetzliche Regelung und richterliche Anwendung, Monatsschrift für Kriminologie und Strafrechtsreform, Årg. 78, s. 312-321.

Sarnecki, J. (1990): Vad kan vi lära oss av Holland?, Apropå, Nr 6, s. 8-10.

SCP 1982 (u.d.): Social and Cultural Report 1982. Rijswijk: Social and Cultural Planning Office.

SCP 1994 (1995): Social and Cultural Report 1994. Rijswijk: Social and Cultural Planning Office.

SCP 2000 (2001): The Netherlands in a European Perspective. Social \& Cultural Report 2000. The Hague: Social and Cultural Planning Office.

Smith, P.D. (1977): Mildness breeds mildness: a look of the Dutch penal system and attitudes. Philadelphia: American Foundation. [Stencil]

SPACE (2002): SPACE I. Council of Europe Annual Penal Statistics. Survey 2001. PC-CP (2002) 1 rev. Strasbourg: Council of Europe.

Steenhuis, D.W., Tigges, L.C.M. \& Essers, J.J.A. (1983): The Penal Climate in The Netherlands: Sunny or Cloudy?, British Journal of Criminology, Årg. 23, s. 1-16.

van Swaaningen, R. \& de Jonge, G. (1995): The Dutch Prison System and Penal Policy in the 1990s: From humanitarian paternalism to penal business management. I: Ruggiero, V., Ryan, M. Sim, J. (red.), Western European Systems, s. 24-45. London: Sage.

Tak, P.J.P. (2001): Sentencing and Punishment in the Netherlands. I: Tonry, M. (red.), Penal Reform in Overcrowded Times, s. 156-161. Oxford/New York: Oxford University Press.

Therborn, G. (1989): 'Pillarization' and 'Popular Movements'. Two Variants of Welfare State Capitalism: the Netherlands and Sweden. I: F.G. Castles, The Comparative History of Public Policy, s. 192-241. Cambridge: Polity Press.

Tonry, M. (2001): Symbol, substance, and severity in western penal policies, Punishment \& Society, Årg. 3, s. 517-536.

Vanderveen, G.N.G. (2001): Nederland vroeger veiliger? De veranderde beleving van onveiligheid, Justitiële verkenningen, Årg. 27, s. 34-48.

Wacquant, L. (1999): "Suitable enemies": Foreigners and immigrants in the prisons of Europe, Punishment and Society, Årg. 1, s. 215-222.

Westfelt, L. (2001): Brott och straff $i$ Sverige och Europa. En studie i komparativ kriminologi. Stockholm: Kriminologiska institutionen/Stockholms universitet. 
Willemse, H.M. (1997): Tio års erfarenheter av brottsförebyggande arbete $i$ Nederländerna. BR $\AA-$ PM 1997:1. Stockholm: Brottsförebyggande rådet.

\begin{abstract}
NOTER
'Artikeln utvidgades senare till en bok under titeln "Contrasts in Tolerance" (Downes, 1988). Boken kritiserades hårt av Franke (1990). Kritiken är på grund av sin detaljrikedom mycket läsvärd. För Downes' svar, se Downes (1990).

${ }^{2}$ Sedan 1987 tillämpas i Holland i princip automatisk 2/3-villkorlig frigivning för strafftider över 6 månader (Kalmthout, 1992:704-709). - Sedan 1999 kan dock en begränsad grupp av fångar med en strafftid på minst ett år villkorligt friges mot att ställas under elektronisk övervakning. För detaljer, se van Kalmthout \& Tak (2001b:178).

${ }^{3}$ Franke (1990) pekar på Jan van Dijks stora betydelse i sammanhanget. - Planen presenterades för övrigt för den nordiska publiken av de Haan (1986).

${ }^{4}$ Begreppet försöker sammanfatta väsentliga drag i holländsk samhällsstruktur (jämförbart med den svenska formeln om "folkhemmet"). I Nationalencyklopedin (Johansson, 1994:87; se även Therborn, 1989) ges följande kortfattade beskrivning: "Det politiska livet i N[ederländerna] har länge, liksom samhällslivet i stort, präglats av Verzuiling-systemet. Benämningen kommer från det nederländska zuil 'pelare' och utgår från att samhället varit starkt uppdelat kring religiös och sociopolitisk tillhörighet, vilket påverkat människors sociala och politiska liv och bestämt t.ex. vilka föreningar man tillhört och hur man har röstat. Uppdelningen har institutionaliserats, och det har uppstått mycket starka intressegrupper. Dessa har setts som de "pelare", på vilket det nederländska samhället vilar, och samspelet och kompromisserna dem emellan har bestämt det politiska livet i N[ederländerna]. [...] Verzuiling-systemet har uppluckrats under de senaste årtiondena [...]".

${ }^{5}$ Problemet tycks dock inte ha lösts. Antalet på grund av platsbrist frigivna häktade uppges exempelvis under perioden 1987-1995 ha varierat mellan 1.200 och 5.300 personer (CBS 1996, Tabell 3.10) och kritiken kvarstår (se för detaljer, Tak \& van Kalmtouth, 2001a:162).

${ }^{6}$ Se t.ex. "Positions of Lijst Pim Fortuyn" (http://www.lijst-pimfortuyn.nl/party.php?goto=english) [2002-08-05]

${ }^{7}$ I mars 2000 uppgavs 35 procent av fångarna i holländska fängelser vara utländska medborgare och totalt 54 procent ha utländsk härkomst (DJI, 2001:15-17). - Se Wacquant (1999) angående situationen $\mathrm{i}$ andra europeiska länder.
\end{abstract}

Not. Artikeln är en väsentlig bearbetning av en tidigare artikel "Fångtal och kriminalpolitik i Holland och Sverige" (von Hofer, 1998).

Adress: Kriminologiska institutionen

Stockholms universitet

S-106 91 Stockholm

E-mail: Hanns.Hofer@crim.su.se 